\title{
Monoamine involvement in the antidepressant-like effect induced by $\mathrm{P} 2$ blockade
}

Diniz, Cassiano R. A. F.

2017

Diniz , C R A F , Rodrigues , M , Casarotto , P C , Pereira , V S , Crestani , C C \& Joca , S R $\mathrm{L} 2017$, ' Monoamine involvement in the antidepressant-like effect induced by P2 blockade ' , Brain Research , vol. 1676 , pp. 19-27 . https://doi.org/10.1016/j.brainres.2017.09.011

http://hdl.handle.net/10138/298058

https://doi.org/10.1016/j.brainres.2017.09.011

publishedVersion

Downloaded from Helda, University of Helsinki institutional repository.

This is an electronic reprint of the original article.

This reprint may differ from the original in pagination and typographic detail.

Please cite the original version. 
Research report

\title{
Monoamine involvement in the antidepressant-like effect induced by P2 blockade
}

\author{
Cassiano R.A.F. Diniz ${ }^{a}$, Murilo Rodrigues ${ }^{b}$, Plínio C. Casarotto ${ }^{c}$, Vítor S. Pereira ${ }^{\text {, }}$, Carlos C. Crestani ${ }^{\text {, }}$ \\ Sâmia R.L. Joca ${ }^{\mathrm{b}, \mathrm{d}, *}$ \\ a Department of Pharmacology, School of Medicine of Ribeirão Preto, University of São Paulo, Brazil \\ ${ }^{\mathrm{b}}$ Department of Physics and Chemistry, School of Pharmaceutical Sciences of Ribeirão Preto, University of São Paulo, Brazil \\ ${ }^{\mathrm{c}}$ Neuroscience Center, University of Helsinki, Finland \\ d Department of Clinical Medicine - Translational Neuropsychiatry Unit, Aarhus University, Denmark \\ ${ }^{\mathrm{e}}$ Laboratory of Pharmacology, School of Pharmaceutical Sciences, UNESP - Universidade Estadual Paulista, Araraquara, Brazil
}

\section{A R T I C L E I N F O}

Article history:

Received 11 April 2017

Received in revised form 6 September 2017

Accepted 8 September 2017

Available online 12 September 2017

\section{Keywords:}

Antidepressant

ATP

Serotonin

Noradrenaline

Forced swimming test

\begin{abstract}
A B S T R A C T
Depression is a common mental disorder that affects millions of individuals worldwide. Available monoaminergic antidepressants are far from ideal since they show delayed onset of action and are ineffective in approximately $40 \%$ of patients, thus indicating the need of new and more effective drugs. ATP signaling through P2 receptors seems to play an important role in neuropathological mechanisms involved in depression, since their pharmacological or genetic inactivation induce antidepressant-like effects in the forced swimming test (FST). However, the mechanisms involved in these effects are not completely understood. The present work investigated monoamine involvement in the antidepressantlike effect induced by non-specific P2 receptor antagonist (PPADS) administration. First, the effects of combining sub-effective doses of PPADS with sub-effective doses of fluoxetine (FLX, selective serotonin reuptake inhibitor) or reboxetine (RBX, selective noradrenaline reuptake inhibitor) were investigated in mice submitted to FST. Significant antidepressant-like effect was observed when subeffective doses of PPADS was combined with subeffective doses of either FLX or RBX, with no significant locomotor changes. Next, the effects of depleting serotonin and noradrenaline levels, by means of PCPA (pChlorophenylalanine) or DSP-4 (N-(2-chloroethyl)-N-ethyl-2-bromobenzylamine hydrochloride) pretreatment, respectively, was investigated. Both, PCPA and DSP-4 pretreatment partially attenuated PPADS-induced effects in FST, without inducing relevant locomotor changes. Our results suggest that the antidepressant-like effect of PPADS involves modulation of serotonin and noradrenaline levels in the brain.
\end{abstract}

(c) 2017 Elsevier B.V. All rights reserved.

\section{Introduction}

World Health Organization (WHO) estimates 350 million of individuals are affected by depression globally, and it predicts depression will be the main cause of morbidity and loss of productivity among all health conditions by 2030 (World Health Organization, 2016). The current antidepressant drug therapy, based on increasing monoamines availability (Elhwuegi, 2004), is only effective in approximately $60 \%$ of the patients, and it takes

\footnotetext{
* Corresponding author at: Department of Physics and Chemistry - School of Pharmaceutical Sciences of Ribeirão Preto (FCFRP), University of São Paulo (USP), AvCafe, s/n, 14040-903 Ribeirão Preto, SP, Brazil.

E-mail addresses: cassianodiniz4@hotmail.com(C.R.A.F.Diniz),murilorodrigues43@ gmail.com (M. Rodrigues), plinio@gmx.com (P.C. Casarotto), vitor.silvapereira@gmail com (V.S. Pereira), cccrestani@yahoo.com.br (C.C. Crestani), samia@usp.br (S.R.L. Joca).
}

3-4 weeks to be clinically effective (Blier, 2003; Racagni and Popoli, 2008).

Great attention has been paid to the purinergic signaling in neuropathological disorders such as Alzheimer and Parkinson disease, anxiety, schizophrenia, drug addiction, and, of importance to the present work, depression, (Abbracchio et al., 2009; Burnstock, 2008). Purinergic neurotransmission emerged from the work of Prof. Burnstock describing adenosine 5'-triphosphate (ATP) as non-adrenergic, non-cholinergic inhibitory transmitter in the guinea-pigs (Abbracchio and Burnstock, 1994; Burnstock, 1972; Burnstock, 1976). Since then, ATP has been described as a cotransmitter in noradrenergic (Sperlagh et al., 1998), gabaergic (Jo and Role, 2002), glutamatergic (Mori et al., 2001) and cholinergic (Richardson and Brown, 1987) synaptic terminals, but vesicles containing exclusively ATP have also been reported (Pankratov et al., 2006). ATP released in synaptic cleft can be degraded by 
ectonucleotidases into various metabolites, such as adenosine, which also acts as a ligand for purinergic receptors (Zimmermann, 2006).

Purinergic neurotransmission comprises receptors for adenosine and ATP, respectively termed P1 and P2. Based on molecular cloning and pharmacological differences, P2 receptors can be divided into P2Y and P2X receptors (Abbracchio and Burnstock, 1994). P2Y are G-protein coupled receptors that modulate inositol-1,4,5-triphosphate (IP3) and diacylglycerol (DAG) levels from membrane phosphoinositide metabolism (Pfeilschifter, 1990; Burnstock, 2007), while P2X are ion channels permeable to $\mathrm{Na}^{+}, \mathrm{K}^{+}$and $\mathrm{Ca}^{2+}$ (Burnstock, 2007; Benham and Tsien, 1987; Bean, 1992). Currently, 8 subtypes of metabotropic P2Y receptors $\left(\mathrm{P}_{2} \mathrm{Y}_{1,2,4,6,11,12,13,14}\right)$ and 7 subtypes of ionotropic P2X receptors $\left(\mathrm{P} 2 \mathrm{X}_{1-7}\right)$ have been described (Burnstock, 2007). P2 receptors are widely expressed in cerebral structures involved in emotional behavior such as hippocampus, cerebral cortex, ventral tegmental area and locus coeruleus (Norenberg and Illes, 2000), either in glial or neuronal cell types (Burnstock, 2008).

It has been recently reported that pharmacological blockade of P2 receptors induces antidepressant-like effects in preclinical models (Pereira et al., 2013; Csolle et al., 2013). Selective P2X7 antagonist also induced antidepressant-like effect in the chronic mild stress model (Iwata et al., 2016) and similar behavioral phenotype was also described in animals with genetic deletion of P2X7 receptors (Boucher et al., 2011; Basso et al., 2009). Despite evidences of an antidepressant-like effect induced by P2R antagonist treatment, the involvement of serotonergic and/or noradrenergic mechanisms has not yet been investigated. Monoamine and purinergic interplay is plausible given the fact that activation of P2R can modulate brain glutamate and NO levels (Florenzano et al., 2008; Pereira et al., 2013), which are both able to control serotonin synthesis, stability and release (Kuhn and Arthur, 1997; Fossier et al., 1999). In support of that, P2X7R knockout animals showed changes in cerebral levels of noradrenaline and serotonin (Csolle et al., 2013). Furthermore, the antidepressant-like effect of NOS inhibitors and NMDA antagonists (Diniz et al., 2016) are dependent of serotonin levels in the brain (Harkin et al., 2003; du Jardin et al., 2016; Ulak et al., 2010). Therefore, since P2R signaling modulate glutamate and NO release in the brain, which then affects monoamine levels, we hypothesized the antidepressant-like effect of the non-specific P2R antagonist PPADS would involve the modulation of brain serotonin and/or noradrenaline levels.

Therefore, the present aims were: 1 . To investigate if the combination of sub-effective doses of P2R antagonist with subeffective doses of antidepressants of different pharmacological classes (serotonin or noradrenaline reuptake inhibitors) would be able to induce antidepressant-like effect in mice submitted to forced swimming test; 2 . To investigate if depleting serotonin or noradrenalin levels, by means of pharmacological pretreatment with PCPA (tryptophan hydroxylase inhibitor; Koe and Weissman, 1966) or DSP4 (noradrenergic neurotoxin; Grzanna et al., 1989), could attenuate or even block the behavioral effect of P2R antagonist in the FST. Altogether, these data could help understanding if monoamines would be involved in the mechanisms underlining the antidepressant-like effect induced by P2R blockade.

\section{Results}

\subsection{Dose-response curves for FLX, RBX and PPADS treatment on mice submitted to FST or OFT}

One-way ANOVA indicates a significant effect of drug treatment on immobility time in the FST $\left[F_{9,60}=3.453\right.$. $\left.p<0.05\right]$. Treatment with PPADS (6.25 mg/kg), FLX (20 mg/kg) and RBX (5 mg/kg) significantly decreased immobility time on FST (Dunn's post hoc test, $\mathrm{p}<0.05)$, as seen in Fig. 1A. Effective doses of PPADS $(6.25 \mathrm{mg} / \mathrm{kg})$, FLX $(20 \mathrm{mg} / \mathrm{kg}$ ) and RBX ( $5 \mathrm{mg} / \mathrm{kg}$ ) were not able to change locomotor behavior of animals tested on OFT (Fig. 1B - F $3_{, 20}=1.715$, non-significant - NS).

\subsection{Add on effects of PPADS sub-effective dose to FLX or RBX sub- effective doses on FST and OFT}

Two-way ANOVA indicates a significant treatment effect of first injection with FLX or RBX $\left[\mathrm{F}_{2,38}=7.831 ; \mathrm{p}<0.01\right]$, of second injection with PPADS $\left[\mathrm{F}_{1,38}=4.534 ; \mathrm{p}<0.05\right]$ and an interaction between factors $\left[\mathrm{F}_{2,38}=4.727 ; \mathrm{p}<0.05\right]$. In column comparison, combination of sub-effective doses of PPADS ( $3 \mathrm{mg} / \mathrm{kg}$ ) and FLX $(10 \mathrm{mg} / \mathrm{kg})$ decreased immobility time compared to $\mathrm{VEH} / \mathrm{VEH}$ $(p<0.05)$ and VEH/PPADS $(p<0.01)$, whereas combination of sub-effective doses of PPADS and RBX $(2.5 \mathrm{mg} / \mathrm{kg})$ decreased immobility time compared to VEH/VEH $(\mathrm{p}<0.01)$, VEH/PPADS $(\mathrm{p}<0.001)$ and RBX/VEH $(\mathrm{p}<0.05)$ groups (Fig. $2 \mathrm{~A}-$ F5,38 $=5.915)$. Combination of sub-effective doses of PPADS $(3 \mathrm{mg} / \mathrm{kg})$ and $\mathrm{FLX}(10 \mathrm{mg} / \mathrm{kg})$ or RBX $(2.5 \mathrm{mg} / \mathrm{kg})$ did not change locomotor activity of animals on OFT (Fig. $2 \mathrm{~B}-\mathrm{F} 2_{, 14}=0.6730$, NS).

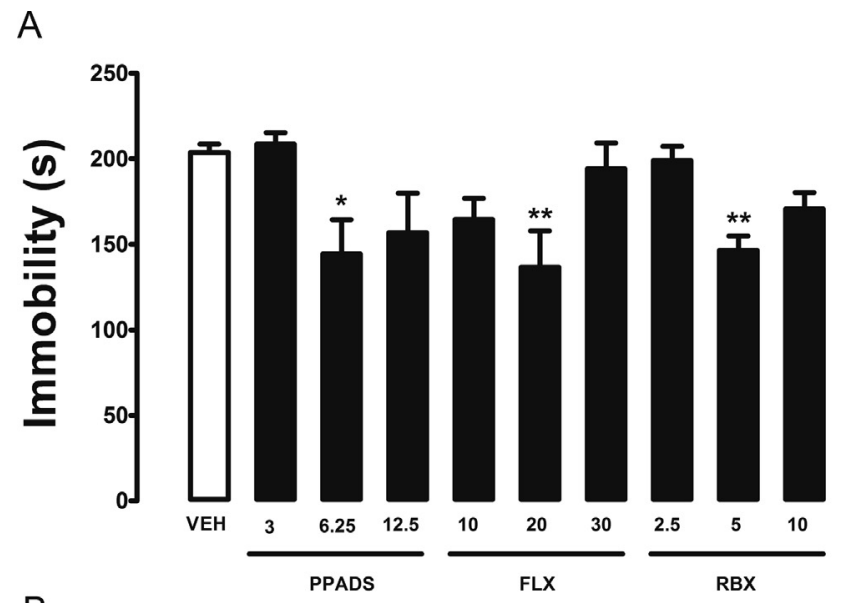

B

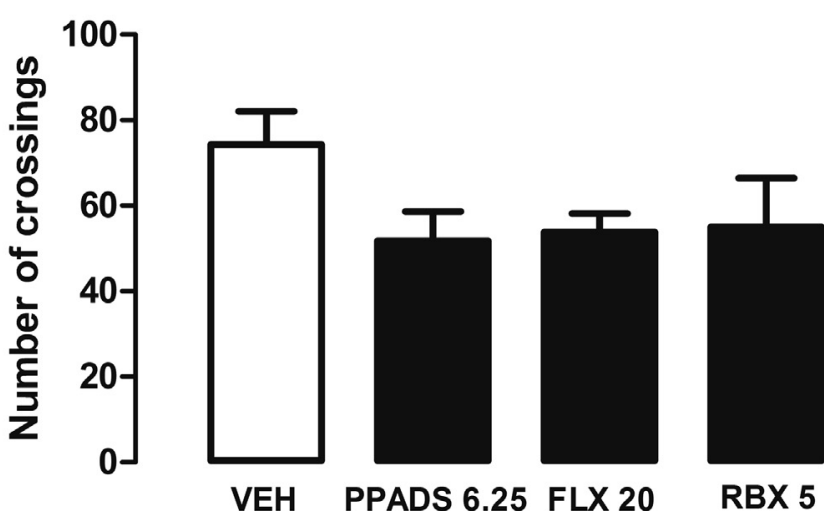

Fig. 1. Dose-response curves for FLX, RBX and PPADS treatment on mice FST and OFT. (A) PPADS $(3,6.25,12.5), \operatorname{FLX}(10,20,30), \operatorname{RBX}(2.5,5,10)$ or vehicle $(10 \mathrm{~mL} / \mathrm{kg})$ were administered 30 min before FST $(n=6,7,7,7,7,5,5,7,10,9$, respectively). Data are expressed as mean \pm SEM of immobility time $(\mathrm{s}) ;{ }^{*} \mathrm{p}<0.05,{ }^{* *} \mathrm{p}<0.01$ from control group. (B) PPADS (6.25 mg/kg, $n=6)$, FLX $(20 \mathrm{mg} / \mathrm{kg}, \mathrm{n}=6), \mathrm{RBX}(5 \mathrm{mg} / \mathrm{kg}$, $\mathrm{n}=6)$ or VEH $(\mathrm{n}=6)$ was administered 30 min before being submitted to OFT. Data are expressed as Mean \pm SEM of total quadrant traveled in the OFT. 


\subsection{Effect of 5-HT depletion on PPADS effects on FST and OFT behavior}

Two-way ANOVA indicated a significant treatment effect of PPADS [ $\left.\mathrm{F}_{1,27}=8.64 ; \mathrm{p}<0.01\right]$ but not of PCPA [ $\left.\mathrm{F}_{1,27}=0.25 ; \mathrm{NS}\right]$, neither interaction between both factors $\left[\mathrm{F}_{1,27}=2.115\right.$; NS]. In column comparison, immobility time of group VEH/PPADS is observed lower than VEH/VEH group $\left[\mathrm{F}_{3,27}=3.631, \mathrm{p}<0.05-\right.$ Fig. $3 \mathrm{~A}$; Dunn's post hoc test]. Moreover, PCPA+VEH, as well as PCPA+PPADS combination did not significantly differ from VEH+VEH group (Fig. 3A; p > 0.05 vs control, Dunn's post hoc test). This indicates PCPA did not induce effect per se, but it attenuated PPADSinduced effects. Two-way ANOVA show no locomotor change
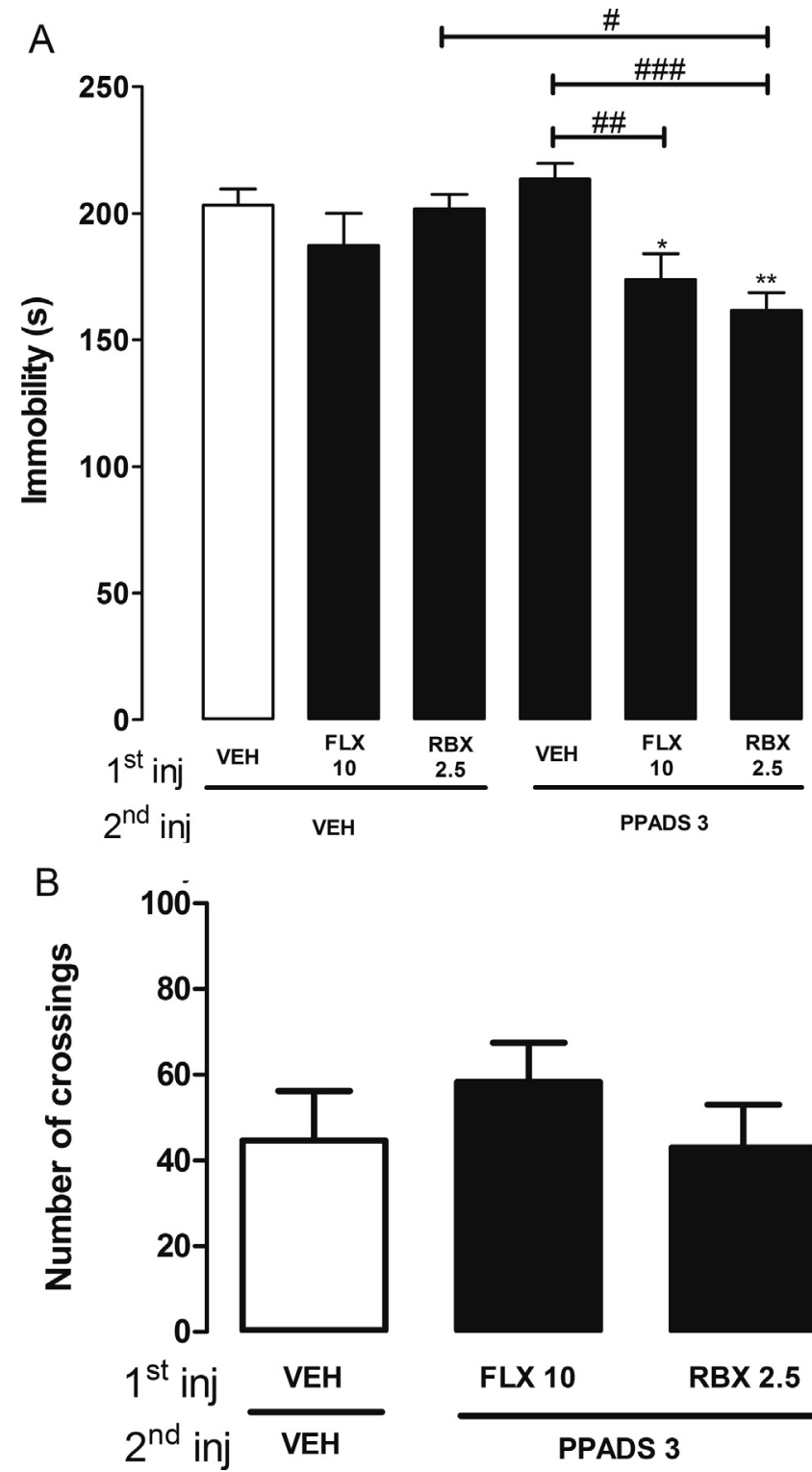

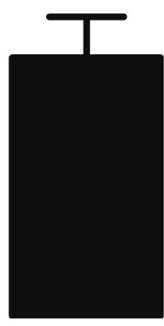

FLX 10

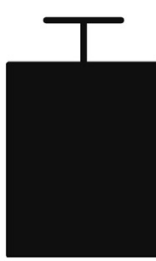

RBX 2.5
PPADS 3

Fig. 2. Add on effects of PPADS sub-effective dose with FLX or RBX sub-effective doses on FST and OFT. (A) Sub-effective dose of FLX (10 mg/kg) or RBX (2.5 mg/kg) was carried out after PPADS sub-effective dose $(3 \mathrm{mg} / \mathrm{kg})$ administration, $30 \mathrm{~min}$ before FST. Six groups were obtained: VEH + VEH $(n=9)$, FLX + VEH $(n=6), \operatorname{RBX}$ $+\operatorname{VEH}(n=6), V E H+\operatorname{PPADS}(n=8), \operatorname{FLX}+\operatorname{PPADS}(n=8), \operatorname{RBX}+\operatorname{PPADS}(n=7)$. Data are expressed as mean \pm SEM of immobility time $(\mathrm{s})$; $" \mathrm{p}<0.05,{ }^{* *} \mathrm{p}<0.01$ from control group; ${ }^{\#} \mathrm{p}<0.05,{ }^{\# \#} \mathrm{p}<0.01,{ }^{\# \# \#} \mathrm{p}<0.001$ from respective groups outlined. (B) Sub-effective dose of FLX (10 mg/kg) or RBX (2.5 mg/kg) was carried after PPADS sub-effective dose ( $3 \mathrm{mg} / \mathrm{kg}$ ) administration, $30 \mathrm{~min}$ before OFT. Three groups were obtained: VEH + VEH $(n=6), \operatorname{FLX}+\operatorname{PPADS}(n=6), \operatorname{RBX}+\operatorname{PPADS}(n=5)$. Data are expressed as Mean \pm SEM of total quadrant traveled in the OFT.

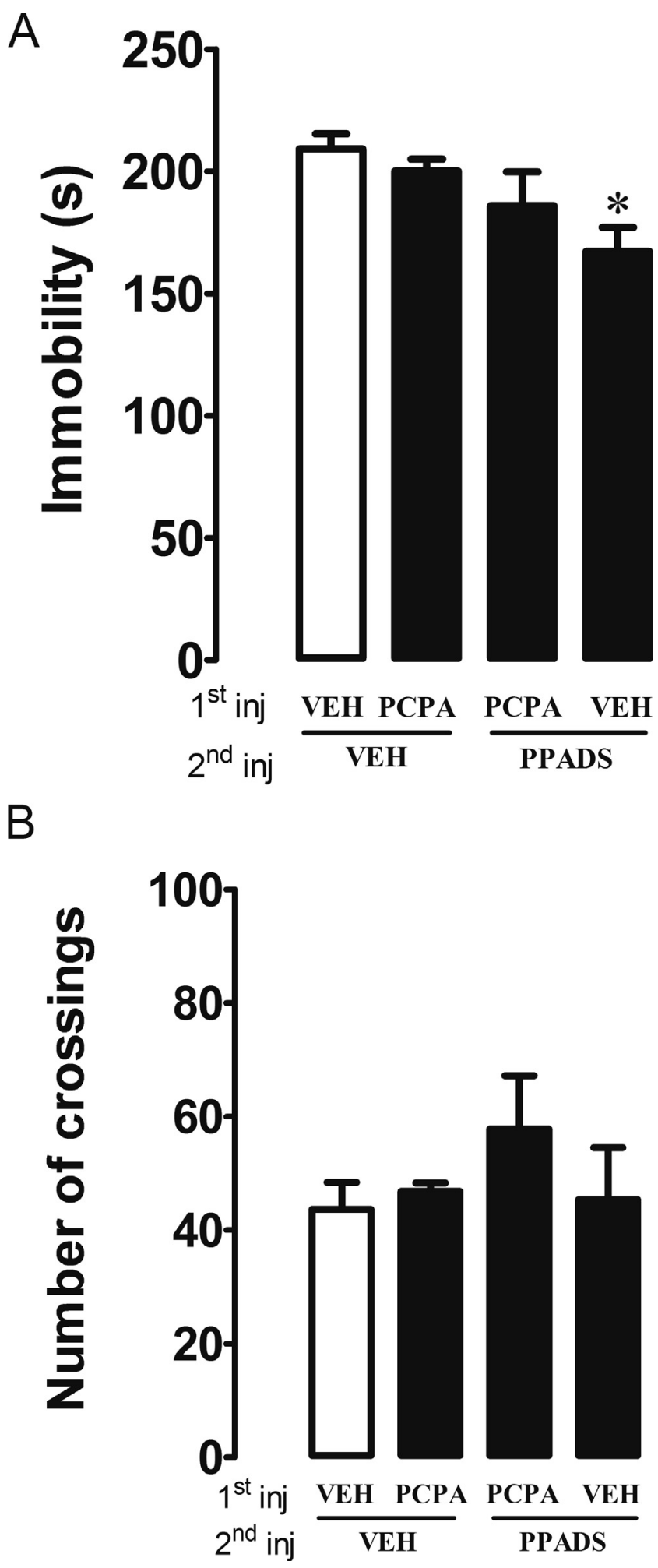

Fig. 3. Effect of 5-HT depletion on PPADS effects on FST and OFT behavior. (A) PCPA $(150 \mathrm{mg} / \mathrm{kg}$ ) or VEH was administered once daily for 4 days. On the fourth day, the last dose of PCPA or VEH infusion were done $30 \mathrm{~min}$ before the second treatment with VEH or PPADS $(6.25 \mathrm{mg} / \mathrm{kg})$. Animals were submitted to the FST $30 \mathrm{~min}$ after the second injection. Thus, four groups were obtained: VEH + VEH $(n=7), P C P A$ + VEH $(n=8)$, PCPA + PPADS $(n=8), V E H+$ PPADS $(n=8)$. Data are expressed as mean \pm SEM of immobility time (s). (B) The same treatment protocol was established as described above, but animals were submitted to the OFT instead of the FST. Four groups were obtained: VEH + VEH $(n=6)$, PCPA + VEH $(n=6)$, PCPA $+\operatorname{PPADS}(n=5), V E H+\operatorname{PPADS}(n=6)$. Data are expressed as Mean \pm SEM of total quadrant traveled in the OFT. ${ }^{*} \mathrm{p}<0.05$ from control group. 
induced by any of the treatments (PCPA: $F_{1,19}=0.859$; NS; PPADS: $F_{1,19}=1.316$; NS; interaction: $F_{1,19}=0.466$; NS - Fig. $3 B$ ).

\subsection{Effect of NA depletion on PPADS effects on FST and OFT}

Two-way ANOVA indicates a significant interaction between DSP4 and PPADS [ $\left.F_{1,31}=8.624 ; \mathrm{p}<0.01\right]$, however no effect of the isolated treatments [DSP4: $F_{1,31}=1.016$; PPADS: $F_{1,31}=1.198$, NS for both]. In column comparison, both groups DSP4/VEH and VEH/PPADS showed decreased immobility time on FST compared to $\mathrm{VEH} / \mathrm{VEH}$ group $\left[\mathrm{F}_{3,31}=3.423, \mathrm{p}<0.05-\right.$ Fig. $\left.4 \mathrm{~A}\right]$. In addition, two-way ANOVA indicated a significant effect of DSP4 $\left[\mathrm{F}_{1,24}=9.58 ; \mathrm{p}<0.005\right]$ but not of PPADS $\left[\mathrm{F}_{1,24}=1.91 ; \mathrm{NS}\right]$ or interaction between factors $\left[\mathrm{F}_{1,24}=1.11\right.$; NS $]$ on OFT. In column comparison, a significant effect of DSP4 infusion on OFT was observed [Fig. 4B - F1,24 $=9.580 ; \mathrm{p}<0.01$ ].

\subsection{HT, NA and 5HIAA levels on PFC and HPC of PCPA and DSP4 treated animals}

According to student's $t$ test there was a significant decrease of $\mathrm{NA}\left(\mathrm{t}_{8}=2.451\right), 5 \mathrm{HIAA}\left(\mathrm{t}_{8}=2.491\right)$ and $5 \mathrm{HT}\left(\mathrm{t}_{8}=3.885\right)$ hippocampal levels in DSP4 treated mice. No difference was observed with DSP4 treatment in frontal cortex (NA $t_{10}=0.018$; 5HIAA $\mathrm{t}_{10}=1.178$ and $\left.5 \mathrm{HT} \mathrm{t}_{10}=1.672\right)$. Student's $t$ test identified a reduction in NA $\left(t_{7}=2.488\right)$ frontal cortex levels from PCPA treatment but no change was observed in 5HIAA $\left(t_{6}=1.100\right)$ and 5HT $\left(t_{7}=1.096\right)$ levels. In hippocampus, 5HIAA $\left(t_{7}=2.647\right)$ levels were significantly reduced by PCPA treatment, but no change was observed in NA $\left(t_{7}=0.159\right)$ and $5 \mathrm{HT}\left(t_{7}=0.490\right)$ levels. All data are found in Table 1.

\section{Discussion}

This work was designed to investigate the involvement of monoamines in PPADS induced antidepressant-like effects in FST. We found that: 1 . Combination of subeffective doses of PPADS with subeffective doses of serotonergic (FLX) or noradrenergic (RBX) antidepressants induced significant effects in mice FST; 2 . Pretreatment with PCPA (serotonin synthesis inhibitor) or DSP-4 (noradrenergic toxin) decreased serotonin and noradrenaline levels in the brain and attenuated PPADS induced antidepressant-like effects. None of these effects were associated to locomotor changes in the OFT.

Stressful events, a key factor for susceptibility to depression, would be expected to affect behavior in the FST. In fact, immobility time of rats exposed to swim session is increased after uncontrollable stress and decreased by antidepressant treatment (Porsolt et al., 1977; Cryan et al., 2002a; Nestler and Hyman, 2010). However, no consensus is established about what immobility in the FST represents, whether it is a behavioral despair or a passivecoping (Cryan et al., 2002a). Either way, the antidepressant efficacy of decreasing immobility time confers to FST a presumable predictive validity and allows the study of mechanism of action for putative new drugs. In this work, systemic treatment with P2R antagonist reduced immobility time in the FST, further supporting the modulation of the purinergic system as a new target for putative antidepressant drugs.

The dose-dependent antidepressant effect induced by PPADS in the present work is in accordance with our previous published paper (Pereira et al., 2013). Further, PPADS co-treatment with FLX and RBX, in subeffective doses, induced a significant antidepressant-like effect, thus suggesting that both serotonergic and noradrenergic mechanisms might participate in PPADSinduced antidepressant-like effects. When two drugs are combined
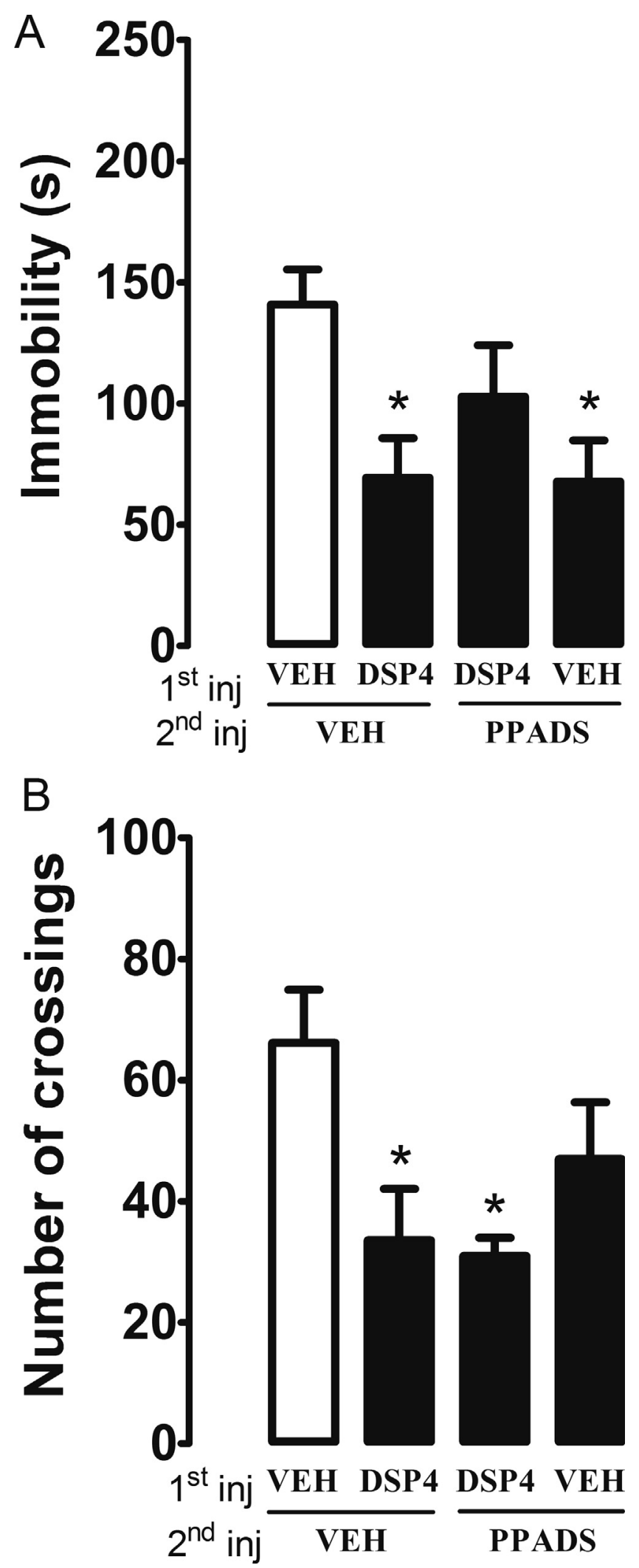

Fig. 4. Effect of NA depletion on PPADS effects on FST and OFT. (A) DSP4 (20 $\mu \mathrm{g})$ was infused i.c.v. $24 \mathrm{~h}$ before FST. Injection of PPADS $(6.25 \mathrm{mg} / \mathrm{kg})$ was performed 30 min before FST. Four groups were obtained: VEH + VEH $(n=7)$, DSP4 + VEH $(n=8)$, DSP4 + PPADS $(n=9), \operatorname{VEH}+\operatorname{PPADS}(n=8)$. Data are expressed as mean \pm SEM of immobility time (s). (B) The same treatment protocol was established as described above, but animals were submitted to the OFT instead of the FST. Four groups were obtained: VEH + VEH ( $n=7)$, DSP4 + VEH ( $n=7)$, DSP4 + PPADS ( $n=7)$ VEH + PPADS $(n=7)$. Data are expressed as Mean \pm SEM of total quadrant traveled in the OFT. ${ }^{*} \mathrm{p}<0.05$ from control group. 
Table 1

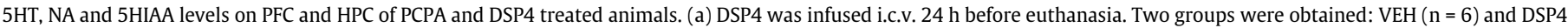

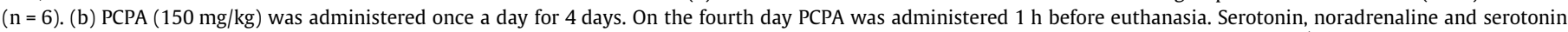

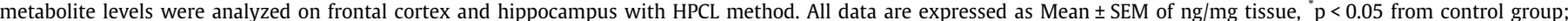

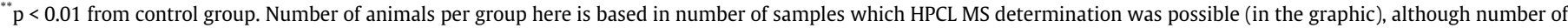
animals euthanized is higher $($ VEH $n=6 / D S P 4 n=6$; VEH $n=5 / \operatorname{PCPA} n=5$ ).

\begin{tabular}{|c|c|c|c|c|c|c|c|c|}
\hline \multicolumn{9}{|c|}{ Neurotransmitter levels } \\
\hline & Vehicle & DSP4 & $t$-test & $\mathrm{p}$ & Vehicle & PCPA & $t$-test & $\mathrm{p}$ \\
\hline \multicolumn{9}{|l|}{ Frontal cortex } \\
\hline Noradrenaline & $0.127 \pm 0.018(n=6)$ & $0.127 \pm 0.010(n=6)$ & $\mathrm{t} 10=0.02$ & 0.98 & $0.049 \pm 0.004(n=4)$ & $0.039 \pm 0.003(n=5)$ & $\mathrm{t} 7=2.49$ & $0.04^{*}$ \\
\hline $5 \mathrm{HT}$ & $0.260 \pm 0.025(n=6)$ & $0.314 \pm 0.020(n=6)$ & $\mathrm{t} 10=1.67$ & 0.12 & $0.087 \pm 0.006(n=4)$ & $0.077 \pm 0.006(n=5)$ & $\mathrm{t} 7=1.10$ & 0.31 \\
\hline 5HIAA & $0.099 \pm 0.017(n=6)$ & $0.121 \pm 0.007(n=6)$ & $\mathrm{t} 10=1.18$ & 0.27 & $0.035 \pm 0.014(n=3)$ & $0.023 \pm 0.002(n=5)$ & $\mathrm{t} 6=1.10$ & 0.31 \\
\hline \multicolumn{9}{|l|}{ Hippocampus } \\
\hline Noradrenaline & $0.237 \pm 0.028(n=5)$ & $0.156 \pm 0.017(n=5)$ & $\mathrm{t} 8=2.45$ & $0.04^{*}$ & $0.080 \pm 0.009(n=4)$ & $0.082 \pm 0.006(n=5)$ & $\mathrm{t} 7=0.16$ & 0.88 \\
\hline $5 \mathrm{HT}$ & $0.324 \pm 0.032(n=5)$ & $0.192 \pm 0.012(n=5)$ & $\mathrm{t} 8=3.88$ & $0.004^{* *}$ & $0.082 \pm 0.012(n=4)$ & $0.076 \pm 0.006(n=5)$ & $\mathrm{t} 7=0.49$ & 0.64 \\
\hline 5HIAA & $0.334 \pm 0.048(\mathrm{~N}=5)$ & $0.207 \pm 0.017(n=5)$ & $\mathrm{t} 8=2.49$ & $0.04^{*}$ & $0.066 \pm 0.007(n=4)$ & $0.048 \pm 0.003(n=5)$ & $\mathrm{t} 7=2.65$ & $0.03^{*}$ \\
\hline
\end{tabular}

in the same organ, they may promote no interference with each other effects, reduce or block each other's action (antagonism), or facilitate each other's action (synergistic or additive effects). Therefore, the combination of subeffective doses of different drugs allows the investigation of "agonistic" drug interactions amongst them (Chou, 2006). Based on that, researchers have used this pharmacological approach as a first step in identifying possible pharmacological interactions that could guide to further investigations on a given drug mechanism of action (Chou, 2006). For instance, Harkin, et al. (2004) demonstrated that the combination of subeffective doses of nNOS inhibitor with subeffective doses of fluoxetine, but not with desipramine, induced effect in the FST, suggesting the participation of serotonergic, but not noradrenergic, mechanisms in the evaluated antidepressant-like effects. This was further confirmed in that study when PCPA pretreatment blocked drug-induced antidepressant effect. Thus, a similar approach was employed in the present study as an attempt to investigate serotonin and noradrenaline involvement on PPADS effects in the FST. Data obtained with depletion studies partially supported the findings with subeffective doses, since both PCPA and DSP-4 attenuated PPADS-induced antidepressant-like effects in the FST.

Absence of per se effect of PCPA on immobility is in agreement with animals and human research regarding monoamine hypothesis of depression. In fact, our data are in agreement with other papers that failed to find effects of PCPA on immobility in the FST and other animal models (O'Leary et al., 2007; Page et al., 1999). Accordingly, serotonin depletion does not precipitate depressive symptoms in health individuals, but blocks the antidepressant effect of serotonergic drugs (Delgado, 2006; Moreno et al., 2010). Similarly, PCPA treatment protocols and results have been described by others where PCPA blocked antidepressant effects in the FST (Harkin et al., 2003; O'Leary et al., 2007).

PCPA is considered a potent depletor of brain serotonin in mice, rats and dogs (Koe and Weissman, 1966). It is well documented that PCPA does not inhibit monoamine oxidase or 5HTPdecarboxylase and it has no effect on monoamine oxidase or 5HTP decarboxylase activity of rat tissues in vivo, thus inducing 5-HT depletion by inhibiting the biosynthesis of this monoamine, possibly by blocking tryptophan hydroxylation (Koe and Weissman, 1966). Other studies have confirmed PCPA acts as a serotonin synthesis inhibitor leading to decreased serotonin levels in different brain regions, depending on dose and treatment schedule (Datla and Curzon, 1996; Kornum et al., 2006).

Regarding DSP4 experiments, a decreased locomotor activity was verified in both DSP4 + VEH and DSP4 + PPADS groups, which might originate from DSP4 effect per se on locomotor activity. In fact, it cannot be excluded that partial reversal of PPADS antidepressive-like effect by DSP4 might be related to a nonspecific DSP4 effect on locomotion. However, that is unlikely, pro- vided DSP4's effect in decreasing locomotor activity did not prevent its own antidepressant-like effect.

DSP-4 mechanism of action is less understood. However, it is known it depletes noradrenaline content in dose-dependent fashion, in different brain regions (Dailly et al., 2006) and rodent species (Fornai et al., 1996). It is reported that after a single i.p. injection of DSP-4, this neurotoxin is uptaken by noradrenergic neurons (Ross and Renyl, 1976; Hallman and Jonsson, 1984), which start to degenerate in the LC target structures (Fritschy and Grzanna, 1989).

Taken together, drugs that inhibit monoamine synthesis or release, such as PCPA and DSP-4 represent important tools that can help characterizing the mechanisms underlying an antidepressant-like effects of a new drug or reveal underlying vulnerability to stress (Cryan et al., 2002b; O'Leary et al., 2007).

In the present work, HPLC analysis of monoamine levels in brain regions of animals treated with PCPA revealed decreased noradrenaline levels in the frontal cortex, while it decreased serotonin main metabolite 5-hydroxyindoleacetic acid (5HIAA) levels in hippocampus. Changes in brain catecholamines after PCPA systemic administration, although subtle, were observed in the original work of Koe and Weissman (1966). Indeed, catecholamine levels can be slightly decreased after PCPA administration, especially in high doses (Koe and Weissman, 1966; Datla and Curzon, 1996; Kornum et al., 2006), as we observed in the present work. Tyrosine hydroxylase was also slightly inhibited in vitro with PCPA infusion and plasma tyrosine levels were slightly reduced after systemic PCPA injection (Koe and Weissman, 1966). Curiously, 5HT levels did not change in either frontal cortex or hippocampus, which is in disagreement with other works (Shutoh et al., 2000; Fletcher et al., 2001; Page et al., 1999). Differences in methodological analysis of serotonin content or in drug administration and brain dissection protocols might explain such contradictory results. Besides, other structures involved with modulation of behavioral consequences of stress such as hypothalamus, bed nucleus of the stria terminalis, nucleus accumbens and amygdala could present serotonin levels changes, but this possibility was not verified in the present work. Although no change was observed on serotonin levels after PCPA treatment, 5HIAA hippocampal levels were decreased. Concentration of 5HIAA has been used to estimate the activity of serotonergic neurons (Shannon et al., 1986). In fact, electrical stimulation of the dorsal raphe nucleus increased 5HIAA levels and 5HIAA/5-HT concentration ratio in the nucleus accumbens, amygdala, suprachiasmatic nucleus and dorsomedial nucleus (Shannon et al., 1986). Therefore, PCPA treatment used in the present work was able to induce changes in both noradrenaline and serotonin neurotransmission in the brain. Based on that, PCPA effects cannot be considered selective to serotonin neurotransmission and its effects on other monoamines should be taken into con- 
sideration when discussing PCPA-induced effects. In addition, even that other have described that similar treatment with PCPA blocked the effect of antidepressant drugs in the FST (Harkin et al., 2003; O'Leary et al., 2007), we observed only partial reversion of PPADS effects in the FST (Fig. 3). This indicates that PPDAS effects might involve monoaminergic mechanisms, although the specific participation of noradrenalin and/or serotonin in PPADS effects is not clear.

DSP4 treatment also decreased not only noradrenaline levels, but also serotonin (5HT) and 5HIAA levels, in the hippocampus. In the frontal cortex, no change was observed on noradrenaline, serotonin or 5HIAA. Although the main neurotoxic effect of DSP4 on noradrenergic neurotransmission (Fornai et al., 1996), other works have described decreased serotonin levels in the cerebellum and in the spinal cord (Jonsson et al., 1981), which is in agreement with our results. It might also seem surprising that DSP-4 decreased neurotransmitter levels in a specific brain region, instead of all over the brain. However, this has been described by others that noradrenergic terminals originated in the locus coeruleus are more susceptible to DSP-4 depleting and neurotoxic effects than those in ventral forebrain and hypothalamus, which are supplied primarily by non-coerulean NE cells (Grzanna et al., 1989). The mechanisms responsible for those differences are not clear, but could rely on differences in the pharmacological properties of NE axon terminals, such as neuronal density and transporter availability (Grzanna et al., 1989). Another reasonable explication is that hippocampus is located close to the ventricular wall, then is possible that i.c.v. drug infusion reached hippocampal region easier than distant areas such as the frontal cortex.

Several reports describe noradrenaline levels are decreased in the brain after systemic injections of DSP4, whereas microdialysis studies indicate extracellular noradrenaline levels are actually increased (for review see Ross and Stenfors, 2015). Other in vivo microdialysis studies (Hughes and Stanford, 1998; Kask et al., 1997) have shown that pretreatment with DSP-4 (40 mg/ kg) actually leads to an increase in the basal extracellular concentration of norepinephrine, in rat frontal cortex, despite causing a $75 \%$ lesion of cortical norepinephrine content. That increase is further potentiated following challenge with the norepinephrine reuptake inhibitor desipramine. Accordingly, augmented behavioral response was seen in reboxetine treated groups after DSP-4 treatment (Cryan et al., 2002b), although an underlying mechanism for that effect remains to be elucidated. Therefore, increased extracellular levels of noradrenaline in some particular brain regions, despite decrements in other brain regions, might help explaining the antidepressant-like effect induced by DSP4 treatment per se. In this sense, DSP4 attenuating effect of PPADS could be the result of a complex interplay between both drugs acting through different brain regions in the CNS.

ATP is recognized as a neurotransmitter accessible to perisynaptic glia and neurons, in addition to being released from glial and neuronal cells (Pascual et al., 2005; Araque et al., 2014; Halassa and Haydon, 2010; Lalo et al., 2014; Kato et al., 2004; Koizumi et al., 2005). This dual functional role of purinergic system contributes to signal integration between glial cells and neuronal synapses, as a tripartite synapse (Pascual et al., 2005). Besides, ATP could evoke astrocyte calcium waves leading to the release of other transmitters such as glutamate, GABA and glycine (Guthrie et al., 1999). In fact, interaction between glutamatergic and purinergic neurotransmission has been the most studied so far, with ATP facilitating neuronal and astrocyte glutamate release (Burnstock, 2002; Burnstock, 2011; Shen et al., 2005).

Glutamate, as well as NO, which arises from NMDAR activation, can control serotonin availability (Kuhn and Arthur, 1997; Fossier et al., 1999). Evidences indicate that ATP itself is also able to attenuate serotonin release in rat brain cortex via P2R activation (Von
Kügelgen et al., 1997). Conversely, serotonin is also able to modulate ATP levels in the brain (Koren-Schwartzer et al., 1994). In this context, the add-on effect observed with concomitant PPADS and FLX administration could derive from P2R blockade favoring serotonergic availability. In addition, a previous work from our group showed PPADS attenuated NO levels in the prefrontal cortex at the same dose that induced antidepressant-like effects in the FST (Pereira et al., 2013). In line with data of the present work, antidepressant-like effect induced by nNOS inhibitors is also dependent on brain serotonin levels (Harkin et al., 2003). In fact, it is known nNOS inhibition can increase the release of 5-TH in the brain (Karolewicz et al., 2001). Altogether, this evidence suggests serotonergic mechanisms might be involved in PPADSinduced antidepressant-like effects. However, pretreatment with PCPA only partially reversed PPADS effect on FST, which suggests that serotonin might be involved in PPADS mechanism, although other neurotransmitters may also play an important role.

Regarding noradrenaline involvement on PPADS effects, it is shown that activation of presynaptic P2R increase the release of noradrenaline in the locus coeruleus (Tschopl et al., 1992), whereas it decreases noradrenaline availability in the rat cortex (von Kügelgen et al., 1994) and hippocampus (Koch et al., 1997). These data reveal a complex role for ATP in regulating noradrenaline levels in the brain. Our results showing that combination of subeffective doses of PPADS with RBX induced antidepressant-like effect suggests the involvement of central noradrenergic mechanisms in PPADS effects on FST. Moreover, the fact that DSP4 was able to reduce PPADS effects, although without blocking it, gives further support to that possibility.

Previous work by Iwata et al. (2016) proposes an alternative mechanism for P2X7-antagonist induced antidepressant-like effects. Their work showed immobilization stress increased glutamate, ATP and inflammatory cytokines levels in hippocampus microdialysates, which was blocked by systemic treatment with P2X7 antagonist. Authors suggested that modulation of inflammasome complex after stress exposure would be involved in the antidepressant-like effect induced by P2X7 blockade. In fact, P2X7 receptors are also expressed in glia and they can trigger inflammasome activation and depressive-like behaviors (Yue et al., 2017). On the other hand, inhibition of inflammasome response seems to be a common mechanism of different antidepressant drugs (Alcocer-Gómez et al., 2017). However, the activation of inflammasome by stress has been shown only after chronic stress exposure (Yue et al., 2017; Iwata et al., 2016; Kaufmann et al., 2017). Since we employed acute stress in mice, it is unlikely this would have played an important role in our experiments. It is, however, possible that blockade of glutamate release from astrocytes by P2X blockade might have contributed to the observed antidepressant effect. However, since neuronal release of ATP is also evidenced (North, 2002) and P2R are expressed either in glial or neuronal cell types (Burnstock, 2008), it is not possible to presume which cell types might have contributed to PPADS effects in the present work. Besides that, the complex and close relationship between glial and neuronal cells mediating purinergic signaling (tripartite synapse) makes cell types discernment harder (Pascual et al., 2005). Nevertheless, it is possible to speculate that different mechanisms and cell types could be involved in acute and chronic effects on P2X7-mediated signaling. Accordingly, the antidepressant-like effect of PPADS, acquired after acute stress exposure, most probably would be provided by direct regulation of ATP activity on P2X7R present in neurons. However, in chronic stress conditions, P2X7 blockade might attenuate depressive-like behaviors by mixed effects, either by blocking ATP/P2X7R binding in astrocytes and thus attenuating neuroinflammatory responses or glutamate release, or by direct regulation of neuronal firing rate. Therefore, blockade of P2X7 
receptors could induce antidepressant-like effects through different mechanisms, depending on the model under investigation (acute vs. chronic stress).

Finally, the results of the present study about serotonin and noradrenalin involvement on PPADS effects should be considered in the light of its limitations. For instance, a parsimonious interpretation must be done regarding the add-on effect of subeffective doses of PPADS plus RBX or FLX, since the combination of subthresholding doses does not necessarily imply a convincing interaction or synergistic effect among two drugs with different mechanism of action (Foucquier and Guedj, 2015). In fact, to assert a reliable synergistic or interaction of mechanism of action between the drugs, an isobologram analysis is required (Tallarida, 2006). Moreover, although PPADS + VEH group was not different from PPADS + PCPA or PPADS + DSP-4, significantly differed from VEH + VEH control group, indicating only partial reversion of PPADS effects without complete blockade. In addition, the complex effect of PCPA and DSP-4 on monoamine levels observed herein is an important limitation of the present study that should also be taken into consideration for the interpretation of the results. Nevertheless, in conclusion, the present study adds further evidence to previous studies, suggesting blockade of P2R induces antidepressantlike effects. Moreover, it suggests the involvement of serotonin and/or noradrenaline in such effects, although further studies regarding purinergic/monoaminergic interplay are still necessary to better understand the pharmacological mechanisms involved on that.

\section{Materials and methods}

\subsection{Animals}

A total of 352 male Swiss mice weighing 30-40 g (6-7 weeks) were used. Animals were housed in groups of 6-8 per cage $\left(570 \mathrm{~cm}^{2}\right)$ in a temperature controlled room $\left(24 \pm 1^{\circ} \mathrm{C}\right)$ under standard laboratory conditions with free access to food and water and a $12 \mathrm{~h}$ light/12 h dark cycle (light on at 6:30 a.m.). Animals were randomly assigned for experimental groups described bellow and procedures were performed in conformity with the Brazilian Council for the Control of Animals under Experiment (CONCEA), which comply with international laws and politics. The local Ethical Committee approved experimental protocol (146/2009), and all efforts to minimize animal suffering were made.

\subsection{Drugs}

Pyridoxalphosphate-6-azophenyl-2', $4^{\prime}$-disulfonic acid tetrasodium salt (PPADS, a non-selective P2R antagonist, Tocris, USA, \#0625), fluoxetine hydrochloride (FLX, selective serotonin reuptake inhibitor, Prati-Donaduzzi, Brazil, \#713198), reboxetine mesylate (RBX, selective noradrenaline reuptake inhibitor, Ascent Scientific, USA, \#157), p-Chlorophenylalanine (PCPA, tryptophan hydroxylase inhibitor, Sigma-Aldrich, EUA, \#C6506), N-(2-chloroe thyl)-N-ethyl-2-bromobenzylamine hydrochloride (DSP4, noradrenergic neurotoxin, TOCRIS, USA, \#2958) were used. All drugs were prepared administered intraperitoneally (i.p.) at $10 \mathrm{~mL} / \mathrm{kg}$, except for DSP4, which was infused intracerobroventricularly in $1 \mu$ l volume. DSP4 and FLX were dissolved in Tween $802 \%$ in sterile saline, while all other drugs were dissolved in sterile isotonic saline. 2,2,2-tribromoethanol (Aldrich Chemical, USA, \#T48402) was used for stereotaxic surgery and chloral hydrate (Sigma Aldrich, USA, \#V000554) was used to euthanize the animals for tissue collection.

\subsection{Forced swimming test (FST)}

Animals were individually submitted to 6 min of forced swimming in glass cylinders (height $25 \mathrm{~cm}$, diameter $17 \mathrm{~cm}$ ) containing $10 \mathrm{~cm}$ of water at $24-26^{\circ} \mathrm{C}$. The test was videotaped and immobility time (characterized by limb movements necessary for floating) was measured during last 4 min of the test by a trained observer blinded to the treatment condition. All behavioral procedures are in accordance to established protocols (Porsolt et al., 1977). The water was changed after each trial (Abel and Bilitzke, 1990).

\subsection{Open field test (OFT)}

The OFT was used to measure locomotor activity of animals according to Zanelati et al. (2010). Mice were placed individually in a circular open field arena $(40 \mathrm{~cm}$ in diameter and $50 \mathrm{~cm}$ high Plexiglas wall) for $6 \mathrm{~min}$. The exploratory activity was videotaped and number of crossings between quadrants was measured during last $4 \mathrm{~min}$ by an observer blinded to the treatment condition. After each trial, arena was cleaned with $70 \%$ alcohol solution.

\subsection{Sample collection and High-performance liquid chromatography (HPLC)}

Animals were deeply anesthetized with chloral hydrate 5\% $(0.75 \mathrm{~g} / \mathrm{kg}$, ip) for brain removal. The frontal cortex and hippocampus were dissected on ice and processed for determination of serotonin, noradrenaline and serotonin metabolite (5HIAA) levels as described by Patel et al. (2005). Samples were homogenized in $0.1 \mathrm{M}$ perchloric acid, afterward centrifuged at $13000 \mathrm{rpm}$ for $10 \mathrm{~min}$ at $4{ }^{\circ} \mathrm{C}$. Supernatant was automatically injected into the chromatographic system to quantify neurotransmitters and metabolites by electrochemical detection in high-performance liquid chromatography (HPLC). The chromatograph (Waters ${ }^{\circledR}$ Alliance) consisted of a stripping column Symmetry ${ }^{\circledR}$ C18, $5 \mu \mathrm{m}$ $(150 \times 4.6 \mathrm{~mm})$ and mobile phase flow $1 \mathrm{ml} / \mathrm{min}$ with the following composition: buffer (88.2\%; citric acid $0.05 \mathrm{M}$, sodium octyl sulfate $250 \mathrm{mg} / \mathrm{L}$, EDTA $0.1 \mathrm{mM}$, potassium chloride $2 \mathrm{mM}$ and $\mathrm{pH}$ adjusted to 3.2 with $\mathrm{NaOH}$ ), methanol (9.3\%) and acetonitrile (2.5\%). Mobile phase was vacuum filtered and degassed ultrasonically. Calibration curve was constructed with standard solutions of $2.5,5,10,25,50,100$ and $200 \mathrm{ng} / \mathrm{ml}$ of norepinephrine, serotonin and 5HIAA, which were injected into the chromatograph in triplicate. Detection and limit of quantification were 0.64 and $2.13 \mathrm{ng} /$ $\mathrm{ml}$ for serotonin; 1.72 and $5.73 \mathrm{ng} / \mathrm{ml}$ for 5HIAA and 0.87 and $2.88 \mathrm{ng} / \mathrm{ml}$ for noradrenaline. Samples with concentrations found below limit of quantitation were discarded. Finally, concentrations of the substances were corrected by the mass of dissected tissue samples being expressed in $\mathrm{ng}$ of substance per $\mathrm{mg}$ of tissue.

\subsection{Stereotaxic surgery and intracerebral administration}

Mice were anesthetized with 2,2,2-tribromoethanol 2.5\% $(10 \mathrm{ml} / \mathrm{kg}$ intraperitoneal, ip) and fixed in a stereotaxic frame. One Stainless steel guide cannula $(0.7 \mathrm{~mm}$ OD) was implanted and aimed at the lateral ventricle (coordinates: anteroposterior $=-0.3 \mathrm{~mm}$ from lambda, lateral $=1.2 \mathrm{~mm}$, dorsoventral $=2.5 \mathrm{~mm}$ ) according to the Paxinos and Franklin's atlas (Paxinos and Franklin, 1997). The cannula tip was placed $1 \mathrm{~mm}$ above site of injection and attached to the skull bone with stainless steel screws and acrylic cement. A stylet inside guide cannula prevented obstruction.

Five to seven days after surgery intra-cerebroventricular (i.c.v) injections were performed with a thin dental needle $(0.3 \mathrm{~mm}$ OD). A volume of $1 \mu \mathrm{l}$ per animal was injected in $30 \mathrm{~s}$ using a micro-syringe (Hamilton) controlled by an infusion pump (Insight 
Equipamentos Científicos, Brazil). A polyethylene catheter (PE10) was interposed between upper end of the dental needle and the micro-syringe. Movement of an air bubble inside the polyethylene catheter confirmed drug flow.

\subsection{Histology}

After the behavioral tests, mice were deeply anesthetized with chloral hydrate $5 \%(0.75 \mathrm{~g} / \mathrm{kg}$, ip) and a dental needle was inserted through the guide cannulae to infuse $0.5 \mu \mathrm{l}$ of methylene blue. Immediately after, animals were euthanized for brain removal. The injection sites were confirmed as correct, on fresh brain, after the dye has spread to the whole brain through cerebroventricular way. Results from injections outside target area were discarded from statistical analysis.

\subsection{Experimental protocols}

\subsubsection{Dose-response curves for FLX, RBX and PPADS treatment on mice} FST and OFT

Experimentally naïve mice received a single ip injection of PPADS (3, 6.25, $12.5 \mathrm{mg} / \mathrm{kg}), \operatorname{FLX}(10,20,30 \mathrm{mg} / \mathrm{kg})$, RBX $(2.5,5$, $10 \mathrm{mg} / \mathrm{kg}$ ) or vehicle and, $30 \mathrm{~min}$ later, submitted to FST. An independent cohort of animals received single ip injections of effective doses of PPADS $(6.25 \mathrm{mg} / \mathrm{kg})$, FLX $(20 \mathrm{mg} / \mathrm{kg}), \mathrm{RBX}(5 \mathrm{mg} / \mathrm{kg})$ or vehicle and submitted to OFT 30 min later.

4.8.2. Add on effects of PPADS sub-effective dose to FLX or RBX subeffective doses on FST and OFT

Independent group of animals received a first injection of saline, FLX $10 \mathrm{mg} / \mathrm{kg}$ or RBX $2.5 \mathrm{mg} / \mathrm{kg}$, immediately followed by a second injection of saline or PPADS $3 \mathrm{mg} / \mathrm{kg}$. Thus, six groups were obtained: VEH+VEH, FLX + VEH, RBX + VEH, PPADS + VEH, FLX + PPADS, RBX + PPADS. Animals were submitted to FST $30 \mathrm{~min}$ after last administration. An independent cohort of animals received ip injections of FLX (10 mg/ $\mathrm{kg}), \mathrm{RBX}(2.5 \mathrm{mg} / \mathrm{kg})$ or vehicle, immediately followed by PPADS ( $3 \mathrm{mg} / \mathrm{kg}$ ), and submitted to OFT 30 min after last administration.

\subsubsection{Effect of 5-HT depletion on PPADS effects on FST and OFT behavior}

Experimentally naïve mice received daily ip injections of PCPA (150 $\mathrm{mg} / \mathrm{kg}$ for 4 days) or VEH. On the fourth day, the last PCPA dose or VEH infusion were done $30 \mathrm{~min}$ before the second injection with VEH or PPADS $(6.25 \mathrm{mg} / \mathrm{kg}$ ). Animals were submitted to FST 30 min after second injection. PCPA dose and infusion schedule were chosen based on a previous work (Haring et al., 2013). An independent cohort of animals was submitted to the same treatment regimen described above and submitted to the OFT $30 \mathrm{~min}$ after second injection.

\subsubsection{Effect of NA depletion on PPADS effects on FST and OFT}

Experimentally naïve mice, with surgically implanted cannula, received i.c.v. infusion of VEH or DSP4 $(20 \mu \mathrm{g})$ followed, 24 h later, by ip injections of PPADS $(6.25 \mathrm{mg} / \mathrm{kg}$ ) or VEH, and submitted to FST 30 min after ip administrations. DSP4 dose was chosen based on a previous work (Choi et al., 2003). An independent cohort of animals was submitted to the same treatment regimen described above and submitted to the OFT 30 min after last injection.

\subsubsection{HT, NA and 5HIAA levels on PFC and HPC of PCPA and DSP4 treated animals}

Experimentally naïve mice received daily ip injections of PCPA (150 $\mathrm{mg} / \mathrm{kg}$ for 4 days) or VEH and euthanized 30min after last administration. An independent cohort of mice, received i.c.v infusion of DSP4 (20 ug) or VEH $24 \mathrm{~h}$ before euthanasia. The levels of
5HT, NA and 5HIAA levels were analyzed on PFC and HPC through HPCL as described.

\subsection{Statistical analysis}

Data from experiment 1 were analyzed in column comparison by one-way ANOVA, followed by Dunnett's post hoc test. Experiments 2 (FST), 3 and 4 were firstly analyzed by two-way ANOVA and injections was described as factors (except for OFT concerning experiment 2 that only One-way ANOVA was used). Thereafter, consecutive any significant difference, a column comparison was performed followed by Newman-Keuls's Multiple comparisons post hoc test. Regarding column comparison, non-parametric Dunn's post hoc test was used when appropriate. Data from experiment 5 was analyzed by Student's $t$ test. Statistical differences were considered significant when $\mathrm{p}<0.05$. SPSS 20.0 software for windows (IBM SPSS statistics ${ }^{\circledR}$, Chicago, IL, USA) was used to the analysis.

\section{Acknowledgements}

The authors would like to thank to Flavia F. Salata and Elisabete Zocal Paro Lepera for her technical support. The present research was supported by grants from FAPESP and CNPq.

\section{Conflict of interest}

The authors declare no conflict of interest.

\section{References}

Abbracchio, M.P. et al., 2009. Purinergic signalling in the nervous system: an overview. Trends Neurosci. 32 (1), 19-29.

Abbracchio, M.P., Burnstock, G., 1994. Purinoceptors: are there families of P2X and P2Y purinoceptors? Pharmacol. Ther. 64 (3), 445-475.

Abel, E.L., Bilitzke, P.J., 1990. A possible alarm substance in the forced swimming test. Physiol. Behav. 48 (2), 233-239.

Alcocer-Gómez, E. et al., 2017. Antidepressants induce autophagy dependentNLRP3-inflammasome inhibition in Major depressive disorder. Pharmacol. Res. $121,114-121$.

Araque, A. et al., 2014. Gliotransmitters travel in time and space. Neuron 81 (4), 728-739.

Basso, A.M. et al., 2009. Behavioral profile of P2X7 receptor knockout mice in animal models of depression and anxiety: Relevance for neuropsychiatric disorders. Behav. Brain Res. 198, 83-90.

Bean, B.P., 1992. Pharmacology and electrophysiology of ATP-activated ion channels. Trends Pharmacol. Sci. 13 (3), 87-90.

Benham, C.D., Tsien, R.W., 1987. A novel receptor-operated Ca2+-permeable channel activated by ATP in smooth muscle. Nature 328 (6127), 275-278.

Blier, P., 2003. The pharmacology of putative early-onset antidepressant strategies. Eur. Neuropsychopharmacol. 13 (2), 57-66.

Boucher, A.A. et al., 2011. Resilience and reduced c-fos expression in P2X7 receptor knockout mice exposed to repeated forced swim test. Neuroscience 189, 170 177.

Burnstock, G., 1972. Purinergic nerves. Pharmacol. Rev. 24 (3), 509-581.

Burnstock, G., 1976. Purinergic receptors. J. Theor. Biol. 62 (2), 491-503.

Burnstock, G., 2002. Purinergic signaling and vascular cell proliferation and death. Arterioscler. Thromb. Vasc. Biol. 22 (3), 364-373.

Burnstock, G., 2007. Purine and pyrimidine receptors. Cell. Mol. Life Sci. 64 (12) $1471-1483$.

Burnstock, G., 2008. Purinergic signalling and disorders of the central nervous system. Nat. Rev. Drug Discov. 7 (7), 575-590.

Burnstock, G., 2011. Purinergic signaling in the gastrointestinal tract. World J. Gastrointest. Pathophysiol. 2 (2), 31-34.

Choi, S.S. et al., 2003. Possible antinociceptivemechanisms of opioid receptor antagonists in the mouse formalin test. Pharmacol. Biochem. Behav. 75, $447-$ 457.

Chou, T.C., 2006. Theoretical basis, experimental design, and computerized simulation of synergism and antagonism in drug combination studies. Pharmacol. Rev. 58 (3), 621-681.

Cryan, J.F., Markou, A., Lucki, I., 2002a. Assessing antidepressant activity in rodents: recent developments and future needs. Trends Pharmacol. Sci. 23 (5), 238-245.

Cryan, J.F., Page, M.E., Lucki, I., 2002b. Noradrenergic lesions differentially alter the antidepressant-like effects of reboxetine in a modified forced swim test. Eur. J. Pharmacol. 436 (3), 197-205. 
Csolle, C. et al., 2013. Neurochemical changes in the mouse hippocampus underlying the antidepressant effect of genetic deletion of P2X7 receptors. PLoS One 8 (6), e66547.

Dailly, E. et al., 2006. Specificity and efficacy of noradrenaline, serotonin depletion in discrete brain areas of Swiss mice by neurotoxins. J. Neurosci. Methods 150 (1), 111-115.

Datla, K.P., Curzon, G., 1996. Effect of p-chlorophenylalanine at moderate dosage on 5-HT and 5-HIAA concentrations in brain regions of control and pchloroamphetamine treated rats. Neuropharmacology 35 (3), 315-320.

Delgado, P.L., 2006. Monoamine depletion studies: implications for antidepressant discontinuation syndrome. J. Clin. Psychiatry 67 (4), 22-26.

Diniz, C.R. et al., 2016. NMDA-NO signaling in the dorsal and ventral hippocampus time-dependently modulates the behavioral responses to forced swimming stress. Behav. Brain Res. 307, 126-136.

Du Jardin, K.G. et al., 2016. Potential involvement of serotonergic signaling in ketamine's antidepressant action: A critical review. Prog. Neuropsychopharmacol. Biol. Psychiatry 71, 27-38.

Elhwuegi, A.S., 2004. Central monoamines and their role in major depression. Prog. Neuropsychopharmacol. Biol. Psychiatry 28 (3), 435-451.

Fletcher, P.J. et al., 2001. Reduced brain serotonin activity disrupts prepulse inhibition of the acoustic startle reflex. Effects of 5,7-dihydroxytryptamine and p-chlorophenylalanine. Neuropsychopharmacology 24 (4), 399-409.

Florenzano, F. et al., 2008. Do ATP and NO interact in the CNS? Prog. Neurobiol. 84 (1), 40-56.

Fornai, F. et al., 1996. Region- and neurotransmitter-dependent species and strain differences in DSP-4-induced monoamine depletion in rodents. Neurodegeneration 5 (3), 241-249.

Fossier, P. et al., 1999. Nitric oxide transforms serotonin into an inactive form and this affects neuromodulation. Neuroscience 93 (2), 597-603.

Fritschy, J.M., Grzanna, R., 1989. Immunohistochemical analysis of the neurotoxic effects of DSP-4 identifies two populations of noradrenergic axon terminals. Neuroscience 30 (1), 181-197.

Grzanna, R. et al., 1989. Acute action of DSP-4 on central norepinephrine axons: biochemical and immunohistochemical evidence for differential effects. J. Histochem. Cytochem. 37 (9), 1435-1442.

Guthrie, P.B. et al., 1999. ATP released from astrocytes mediates glial calcium waves. J. Neurosci. 19 (2), 520-528.

Halassa, M.M., Haydon, P.G., 2010. Integrated brain circuits: astrocytic networks modulate neuronal activity and behavior. Annu. Rev. Physiol. 72, 335-355.

Hallman, H., Jonsson, G., 1984. Pharmacological modifications of the neurotoxic action of the noradrenaline neurotoxin DSP4 on central noradrenaline neurons. Eur. J. Pharmacol. 103 (3-4), 269-278.

Haring, M. et al., 2013. Cannabinoid $\mathrm{CB}_{1}$ receptor in the modulation of stress coping behavior in mice: the role of serotonin and different forebrain neuronal subpopulations. Neuropharmacology 65, 83-89.

Harkin, A. et al., 2003. Serotonergic mediation of the antidepressant-like effects of nitric oxide synthase inhibitors. Neuropharmacology 44 (5), 616-623.

Harkin, A. et al., 2004. Nitric oxide synthase inhibitors augment the effects of serotonin re-uptake inhibitors in the forced swimming test. Eur. Neuropsychopharmacol. 14 (4), 274-281.

Hughes, Z.A., Stanford, S.C., 1998. Evidence from microdialysis and synaptosomal studies of rat cortex for noradrenaline uptake sites with different sensitivities to SSRIs. Br. J. Pharmacol. 124 (6), 1141-1148.

Iwata, M. et al., 2016. Psychological stress activates the inflammasome via release of adenosine triphosphate and stimulation of the purinergic Type $2 \mathrm{X} 7$ receptor Biol. Psychiatry 80 (1), 12-22.

Jo, Y.H., Role, L.W., 2002. Cholinergic modulation of purinergic and GABAergic cotransmission at in vitro hypothalamic synapses. J. Neurophysiol. 88 (5), 2501 2508.

Jonsson, G. et al., 1981. DSP4 (N-(2-chloroethyl)-N-ethyl-2-bromobenzylamine) - a useful denervation tool for central and peripheral noradrenaline neurons. Eur. J. Pharmacol. 72 (2-3), 173-188.

Foucquier, J., Guedj, M., 2015. Analysis of drug combinations: current methodological landscape. Pharmacol. Res. Perspect. 3 (3), e00149.

Karolewicz, B. et al., 2001. Effect of NOS inhibitor on forced swim test and neurotransmitters turnover in the mouse brain. Pol. J. Pharmacol. 53 (6), 587-596.

Kask, A. et al., 1997. Overflow of noradrenaline and dopamine in frontal cortex after [N-(2-chloroethyl)-N-ethyl-2-bromobenzylamine] (DSP-4) treatment: in vivo microdialysis study in anaesthetized rats. Naunyn. Schmiedebergs Arch. Pharmacol. 355 (2), 267-272.

Kato, F. et al., 2004. ATP- and adenosine-mediated signaling in the central nervous system: synaptic purinoceptors: the stage for ATP to play its "dual-role". J. Pharmacol. Sci. 94 (2), 107-111.

Kaufmann, F.N. et al., 2017. NLRP3 inflammasome-driven pathways in depression: Clinical and preclinical findings. Brain Behav. Immun. 64, 367-383.

Koch, H., Von Kügelgen, L., Starke, K., 1997. P2-receptor-mediated inhibition of noradrenaline release in the rat hippocampus. Naunyn. Schmiedebergs Arch Pharmacol. 355 (6), 707-715.

Koe, B.K., Weissman, A., 1966. p-Chlorophenylalanine: a specific depletor of brain serotonin. J. Pharmacol. Exp. Ther. 154 (3), 499-516.

Koizumi, S., Fujishita, K., Inoue, K., 2005. Regulation of cell-to-cell communication mediated by astrocytic ATP in the CNS. Purinergic Signal. 1 (3), 211-217.

Koren-Schwartzer, N. et al., 1994. Serotonin-induced decrease in brain ATP stimulation of brain anaerobic glycolysis and elevation of plasma hemoglobin; the protective action of calmodulin antagonists. Gen. Pharmacol. 25 (6), 1257-1262.
Kornum, B.R. et al., 2006. Central serotonin depletion affects rat brain areas differently: a qualitative and quantitative comparison between different treatment schemes. Neurosci. Lett. 392 (1-2), 129-134.

Kuhn, D.M., Arthur Jr, R., 1997. Molecular mechanism of the inactivation of tryptophan hydroxylase by nitric oxide: attack on critical sulfhydryls that spare the enzyme iron center. J. Neurosci. 17 (19), 7245-7251.

Lalo, U. et al., 2014. Exocytosis of ATP from astrocytes modulates phasic and tonic inhibition in the neocortex. PLoS Biol. 12 (1), e1001747.

Moreno, F.A. et al., 2010. CSF neurochemicals during tryptophan depletion in individuals with remitted depression and healthy controls. Eur. Neuropsychopharmacol. 20 (1), 18-24.

Mori, M. et al., 2001. Fast synaptic transmission mediated by P2X receptors in CA3 pyramidal cells of rat hippocampal slice cultures. J. Physiol. 535 (Pt 1), 115-123.

Nestler, E.J., Hyman, S.E., 2010. Animal models of neuropsychiatric disorders. Nat. Neurosci. 13 (10), 1161-1169.

Norenberg, W., Illes, P., 2000. Neuronal P2X receptors: localisation and functional properties. Naunyn. Schmiedebergs Arch. Pharmacol. 362 (4-5), 324-339.

North, 2002. Molecular physiology of P2X receptors. Physiol. Rev. 82 (4), $1013-$ 1067.

O'Leary, O.F. et al., 2007. Depletion of serotonin and catecholamines block the acute behavioral response to different classes of antidepressant drugs in the mouse tail suspension test. Psychopharmacology 192 (3), 357-371.

Page, M.E. et al., 1999. Serotonergic mediation of the effects of fluoxetine, but not desipramine, in the rat forced swimming test. Psychopharmacology (Berl) 147 (2), 162-167.

Pankratov, Y. et al., 2006. Vesicular release of ATP at central synapses. Pflugers Arch. 452 (5), 589-597.

Pascual, O. et al., 2005. Astrocytic purinergic signaling coordinates synaptic networks. Science 310 (5745), 113-116.

Patel, B.A. et al., 2005. Simple and rapid determination of serotonin and catecholamines in biologcal tissue using high-performance liquid chromatography with electrochemical detection. J. Chromatogr. B Anal. Technol. Biomed. Life Sci. 818 (2), 269-276.

Paxinos, G., Franklin, K.B.J., 1997. The Mouse Brain in Stereotaxic Coordinates. Academic, San Diego.

Pereira, V.S. et al., 2013. Antidepressant- and anticompulsive-like effects of purinergic receptor blockade: involvement of nitric oxide. Eur. Neuropsychopharmacol. 23 (12), 1769-1778.

Pfeilschifter, J., 1990. Extracellular ATP stimulates polyphosphoinositide hydrolysis and prostaglandin synthesis in rat renal mesangial cells. Involvement of a pertussis toxin-sensitive guanine nucleotide binding protein and feedback inhibition by protein kinase C. Cell. Signal. 2 (2), 129-138.

Porsolt, R.D., Bertin, A., Jalfre, M., 1977. Behavioral despair in mice: a primary screening test for antidepressants. Arch. Int. Pharmacodyn. Ther. 229 (2), 327336.

Racagni, G., Popoli, M., 2008. Cellular and molecular mechanisms in the long-term action of antidepressants. Dialogues Clin. Neurosci. 10 (4), 385-400.

Richardson, P.J., Brown, S.J., 1987. ATP release from affinity-purified rat cholinergic nerve terminals. J. Neurochem. 48 (2), 622-630.

Ross, S.B., Renyl, A.L., 1976. On the long-lasting inhibitory effect of $\mathrm{N}-(2$ chloroethyl)-N-ethyl-2-bromobenzylamine (DSP 4) on the active uptake of noradrenaline. J. Pharm. Pharmacol. 28 (5), 458-459.

Ross, S.B., Stenfors, C., 2015. DSP4, a selective neurotoxin for the locus coeruleus noradrenergic system. A review of its mode of action. Neurotoxic. Res. 27 (1), $15-30$.

Shannon, N.J. et al., 1986. A comparison of biochemical indices of 5hydroxytryptaminergic neuronal activity following electrical stimulation of the dorsal raphe nucleus. J. Neurochem. 47 (3), 958-965.

Shen, J. et al., 2005. Involvement of the nitric oxide-cyclic GMP pathway and neuronal nitric oxide synthase in ATP-induced Ca2+ signalling in cochlear inner hair cells. Eur. J. Neurosci. 21 (11), 2912-2922.

Shutoh, F. et al., 2000. Long term depletion of serotonin leads to selective changes in glutamate receptor subunits. Neurosci. Res. 38 (4), 365-371.

Sperlagh, B. et al., 1998. Co-release of endogenous ATP and [3H]noradrenaline from rat hypothalamic slices: origin and modulation by alpha2-adrenoceptors. Neuroscience 82 (2), 511-520.

Tallarida, R.J., 2006. An overview of drug combination analysis with isobolograms. J. Pharmacol. Exp. Ther. 319 (1), 1-7.

Tschopl, M. et al., 1992. Excitatory effects of adenosine 5'-triphosphate on rat locus coeruleus neurones. Eur. J. Pharmacol. 213 (1), 71-77.

Ulak, G. et al., 2010. Involvement of serotonin receptor subtypes in the antidepressant-like effect of TRIM in the rat forced swimming test. Pharmacol. Biochem. Behav. 95 (3), 308-314.

Von Kügelgen, L., Späth, L., Starke, K., 1994. Evidence for P2-purinoceptor-mediated inhibition of noradrenaline release in rat brain cortex. Br. J. Pharmacol. 113 (3), 815-822.

Von Kügelgen, L., Koch, H., Starke, K., 1997. P2-receptor-mediated inhibition of serotonin release in the rat brain cortex. Neuropharmacology 36 (9), 1221-1227.

Zimmermann, H., 2006. Ectonucleotidases in the nervous system. Novartis Found Symp 276: pp. 113-128; discussion 128-30, 233-7, 275-81.

Zanelati, T.V. et al., 2010. Antidepressant-like effects of cannabidiol in mice: possible involvement of 5-HT1A receptors. Br. J. Pharmacol. 159 (1), 122-128.

World Health Organization. Online Media centre. Reviewed April 2016.

Yue, N. et al., 2017. Activation of P2X7 receptor and NLRP3 inflammasome assembly in hippocampal glial cells mediates chronic stress-induced depressive-like behaviors. J. Neuroinflammation 14 (1), 102. 